\title{
APRESENTAÇÃO DA CONSTRUÇÃO DOS PARÂMETROS À APLICAÇÃO DO MODOELO CONCEITUAL TRIDIMENSIONAL DE PERFORMANCE SOCIAL DE CARROLL
}

\author{
PRESENTATION OF THE CONSTRUCTION OF THE \\ PARAMETERS TO THE APPLICATION OF THE THREE- \\ DIMENSIONAL CONCEPTUAL MODEL OF SOCIAL \\ PERFORMANCE OF CARROLL
}

\author{
Recebido 13-11-2012 \\ Aceito 26-05-2013 \\ Nívea Marcela Marques Nascimento Macêdo ${ }^{1}$ \\ Maria Albenisa Gadelha² \\ Gesinaldo Ataíde Cândido ${ }^{3}$
}

\section{RESUMO}

A responsabilidade social das empresas (RSE) é um tema relevante na atualidade. Ele explora um novo papel para as organizações direcionado ao alcance dos interesses individuais e coletivos dos que fazem parte do negócio e às suas contribuições para a construção de um contexto mais equitativo e equilibrado para as sociedades. A RSE deve trabalhar considerando as características e necessidades de seus stakeholders. Desse modo, no atual mercado, as empresas têm de atuar a partir das percepções dos que fazem parte dela e ajudam a manter sua competitividade. O modelo de Carroll (1979), que se constitui em uma das principais abordagens teóricas da RSE, discute o papel e a relevância dos stakeholders a partir de práticas de RSE em uma organização. Assim, neste estudo, objetiva-se apresentar como se deu a construção dos parâmetros e das variáveis para a aplicabilidade do referido modelo nas organizações. Tal aplicação permite a uma empresa avaliar e aperfeiçoar suas práticas de gestão social. Um estudo exploratório na literatura relacionado ao tema proporcionou a construção de variáveis e instrumentos de pesquisa específicos que podem ser empregados em empresas que possuem a responsabilidade social em suas ações. Os resultados evidenciam as características principais de cada item das dimensões do modelo, sejam elas refrentes às categorias legal, discricionária e voluntária, o que permite à empresa avaliar seus resultados, diagnosticar oportunidades e desafios e administrar seus pontos fracos, bem como gerir suas atividades sociais de forma que seus stakeholders tenham uma compreensão fidedigna da realidade e tenham suas necessidades corretamente compreendidas.

Palavras-chave: Responsabilidade Social Empresarial; Modelo Tridimensional de Carroll (1979); Gestão de Stakeholders.

\footnotetext{
${ }^{1}$ Possui graduação em Administração pela Universidade Estadual da Paraíba - UEPB e mestrado em Engenharia de Produção pela Universidade Federal da Paraíba - UFPB. Atualmente é professora assistente da Universidade Federal da Paraíba. Rio Tinto, Paraíba, Brasil. E-mail: niveamarcela@ig.com.br.

${ }^{2}$ Possui graduação em Administração pela Faculdade Integrada do Ceará - FIC, especialização em Gestão Empreendedora e em Engenharia de Produção pelo Instituto Centro de Ensino Tecnológico - CENTEC e mestrado em Engenharia de Produção pela Universidade Federal da Paraíba - UFPB. Fortaleza, Ceará, Brasil. Email: benaonix@hotmail.com.

${ }^{3}$ Possui graduação e mestrado em Administração pela Universidade Federal da Paraíba - UFPB e doutorado em Engenharia de Produção pela Universidade Federal de Santa Catarina - UFSC. Atualmente é professor titular da Universidade Federal de Campina Grande - UFCG. Campina Grande, Paraíba, Brasil. Email: gacandido@uol.com.br.
} 


\section{ABSTRACT}

The social responsibility of the companies $(S R C)$ is at the present time an important theme. It explores a new paper for the organizations addressed to the reach of the individual and collective interests of the ones that are part of the business and to your contributions for the construction of a more equal context for the societies. SRC should work considering the characteristics and needs of your stakeholders. In the current market, the companies have to act starting from the perceptions of the ones that are part of her and help to maintain your competitiveness. The model of Carroll (1979), that is one of the main theoretical approaches of SRC, discusses the paper and relevance of the stakeholders starting from practices of SRC in an organization. The results show the main features of each item of the model dimensions, whether in the legal, voluntary and discretionary categories, which allows the company to assess its results, diagnose opportunities and challenges and manage their weaknesses, manage their social activities so that stakeholders have an accurate understanding of reality and have their needs properly understood.

Keywords: Managerial Social Responsibility; Three-dimensional Carroll's Model (1979); Stakeholders Administration.

\section{INTRODUÇÃO}

A complexidade do atual ambiente de negócios traz a necessidade de as organizações repensarem suas formas de atuação, em especial, junto aos atores sociais e institucionais com os quais mantêm os seus diversos tipos de vínculos e relacionamentos. É nesse contexto que surge o tema Responsabilidade Social Empresarial (RSE), o qual explora um novo papel para as empresas, direcionado ao alcance dos interesses individuais e coletivos dos que fazem parte do negócio e às suas contribuições para a construção de um contexto mais equitativo e equilibrado.

A RSE envolve a consideração e o trabalho de grupos de pessoas distintas: os stakeholders - fornecedores, consumidores, clientes, comunidade, funcionários, diretores, acionistas e parceiros. As necessidades, interferências e percepções dessas pessoas perante uma organização precisam ser consideradas para a eficiência do negócio.

A manutenção de relacionamentos sustentáveis por parte do negócio com seus principais agentes relacionados consiste em uma das principais questões estratégicas das empresas. Assim, torna-se relevante estruturar meios que proporcionem a verificação da percepção e do entendimento dos stakeholders com os negócios de que fazem parte. Atualmente, poucos modelos de RSE ajudam a avaliar na prática o que as empresas têm feito nesse sentido. Sob a perspectiva da mensuração da percepção dos agentes envolvidos com uma empresa, verifica-se a relação que a RSE mantém com a gestão de stakeholders, uma vez que, para a correta atuação socialmente responsável por parte das empresas, é necessário que elas considerem as principais características e necessidades dos atores envolvidos.

O estudo teórico e empírico da RSE no cenário nacional e internacional mostra diversas abordagens que procuram conceituar o tema e desenvolvê-lo como forma de melhor entendê-lo e evidenciá-lo nas organizações. O modelo tridimensional de performance social desenvolvido por Carroll em 1979 constitui-se em uma das principais abordagens da RSE no âmbito teórico, não sendo possível observar com maior ênfase mecanismos que possam garantir a efetividade de seu conceito na prática. Este modelo permite, com o devido preenchimento das lacunas existentes desde sua criação em 1979, conhecer ou identificar a percepção de todo um conjunto de pessoas envolvidas com uma empresa, seus stakeholders, sobre sua atuação social e sobre como essas ações estão impactando o ambiente interno e externo à organização. Permite, ainda, verificar como tais ações podem ser melhor desenvolvidas para estar de acordo com as necessidades e características dos stakeholders. 
Desse modo, dada a importância do modelo em questão na literatura da RSE, bem como o fato de existirem poucos estudos que avaliem a RSE na prática, objetiva-se apresentar, nesta pesquisa, como se deu a construção dos parâmetros e das variáveis para a aplicabilidade do modelo de Carroll (1979). Ressalta-se que um estudo preliminar sobre tal modelo pode ser observado em Macêdo e Cândido (2011), que promoveram uma pesquisa qualitativa a partir da aplicação de Carroll (1979) em uma empresa têxtil do estado da Paraíba. Assim, a partir da consecução deste objetivo, é possível observar como ocorreu o estudo das variáveis e sua construção, contribuindo tanto à gestão das empresas como ao estudo teórico sobre o tema.

Esta pesquisa pode evidenciar, portanto, como é possível promover maior praticidade ao tema RSE e aos seus modelos teóricos ou empíricos, principalmente a partir da apresentação dos principais modelos e abordagens da Responsabilidade Social, bem como proporcionar às empresas um modelo prático para avaliar suas ações de RSE com base na percepção das próprias pessoas participantes do contexto.

Para realização deste objetivo, apresenta-se primeiramente uma abordagem teórica sobre a RSE, sobre a teoria dos stakeholders e sobre o modelo conceitual tridimensional de performance social de Carroll (1979). Posteriormente, são apresentadas as variáveis e sua descrição e os parâmetros criados para a aplicabilidade do referido modelo em relação a instrumentos de pesquisa específicos. Em seguida, são trazidas à tona as conclusões, as considerações finais e as referências.

\section{FUNDAMENTOS TEÓRICOS}

\subsection{Responsabilidade Social Empresarial}

O comportamento ético e moral tem norteado as ações empresariais da atualidade. Muitas empresas mostram maior consideração e preocupação em proporcionar um ambiente confortável e adequado para o trabalho, formando um cenário em que a transparência e a responsabilidade passam a ser mais importantes.

Além disso, os agentes envolvidos com as organizações apresentam maior interesse em sua atuação no mercado e suas práticas para com uma série de atores relacionados. Essas características vêm alterando as relações entre empresas e agentes internos e externos, uma vez que tais relações estão obtendo maiores proporções e influências na organização.

É nesse sentido que a RSE se torna um tema necessário em termos estratégicos para as organizações. Dean (2003) propõe que as empresas que buscam adotar uma postura socialmente responsável a fazem por meio da obediência a leis e normas éticas, do tratamento justo aos empregados, de cuidados com o meio ambiente e de contribuições para ações sociais.

Para Heal (2005), a RSE envolve a adoção de ações que reduzem a extensão de custos distintos ou evitam a generalização de conflitos. Para o autor, esta definição é diferente de muitas já oferecidas. Segundo ele, a maioria dos conceitos mostra que empresas socialmente responsáveis apresentam o desejo voluntário de contribuir com uma sociedade melhor e um ambiente mais limpo.

Outros conceitos indicam que a RSE se preocupa com o tratamento ético dos stakeholders da firma de uma maneira responsável. Algumas definições englobam, ainda, o papel do governo e os tipos de contrato entre a organização e os grupos de pessoas envolvidas. A consideração da RSE por parte de uma empresa está relacionada à sua própria cultura e características e aos tipos de relações que mantém com seus stakeholders. McWilliams e Siegel (2001) consideram que a empresa socialmente responsável deve investir em ações que visem promover benefícios sociais que vão além da geração de lucros e do cumprimento de leis. 
Nesse sentido, observa-se que a RSE envolve posturas que vão além da consideração de aspectos legais. Mohr, Webb e Harris (2001) acreditam que o conceito de RSE é amplo e que é esperado que exista uma variedade de significados relacionados ao termo. Para os autores, existem dois grupos de definições para responsabilidade social. O primeiro engloba uma definição multidimensional, mais pontuada por Carroll (1991); o segundo abarca uma definição baseada no conceito de marketing de sociedade, a qual propõe à RSE um nível mais abstrato. Os autores, por sua vez, definem RSE como o compromisso de uma companhia para minimizar ou eliminar qualquer efeito prejudicial e maximizar seus impactos benéficos na sociedade.

Constata-se que a atenção às relações de um conjunto de envolvidos é o cerne da adoção de uma postura socialmente responsável por parte de uma empresa. A correta gestão de stakeholders faz parte da estratégia de negócios para o sucesso. Sua interpretação e interferência nas transações comerciais precisam ser consideradas, uma vez que podem validar ou não a atuação da empresa. Assim, a RSE deve trabalhar no sentido de colocar-se como uma prática consolidada e que possa proporcionar benefícios em longo prazo.

É necessária a consideração ética de todas as interações com os grupos de envolvidos. Nos dias de hoje, a visão da responsabilidade social da empresa é diferente. Para Grajew (2001), a RSE incorpora-se à gestão e abrange toda a cadeia de relacionamentos: funcionários, clientes, fornecedores, investidores, governo, concorrentes, acionistas, meio ambiente e comunidade em geral. Diante disso, abordagens que considerem as especificidades dos stakeholders de uma organização são válidas e consequentes da correta adoção da RSE.

\subsection{Teoria dos stakeholders}

A teoria dos stakeholders denota o entendimento de que os negócios possuem responsabilidades com todo um conjunto de partes interessadas, ou seja, com os indivíduos que de alguma maneira fazem parte da "existência" do negócio. A teoria mostra que os resultados das atividades organizacionais necessitam considerar o devido retorno a todos os grupos de indivíduos (stakeholders) envolvidos com a organização (MACEDO, CÂNDIDO, 2011).

Para que a empresa obtenha eficiência e sobreviva aos concorrentes é importante que todos os atores sejam administrados em suas necessidades e seus níveis de influência para com a organização. A premissa fundamental dessa teoria, segundo Wilson (2000), é que, quanto mais fortes forem as relações de uma organização com seus parceiros externos e internos, mais fácil será para essa organização alcançar seus objetivos corporativos.

A Figura 1 procura explanar de modo mais claro a interpretação das formas de relação entre os agentes e a organização.

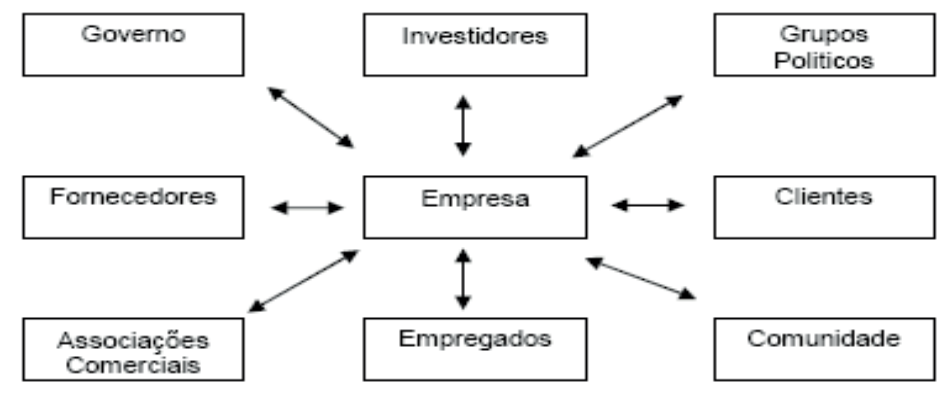

Figura 1: Modelo baseado na interação com stakeholders Fonte: Donaldson; Preston, (1995) 
De acordo com a teoria dos stakeholders, à medida que os gestores procuram introduzir ações sociais nas empresas ocorre a necessidade de contemplar todo um conjunto de indivíduos relacionados, que atuam direta e indiretamente com a empresa e são por ela influenciados, bem como a necessidade de considerar as prioridades desses indivíduos e seus níveis de poder na organização. Donaldson e Preston (1995) argumentam que a função da teoria dos stakeholders seria, portanto, explicar o funcionamento de uma organização e guiar sua operação frente a vários relacionamentos.

Para isso, faz-se importante verificar, a princípio, quais são esses agentes relacionados, aqueles que fazem parte da "linha de frente" da firma, e qual é a atuação desses agentes. Existem alguns autores que veem como stakeholders da empresa um leque restrito de atores, conforme a proposta de Friedman (1970); outros autores já incorporam um número maior desses atores, como Clarkson (1995) e Donaldson e Preston (1995); e outros autores têm uma concepção larga dos atores envolvidos com a empresa, tais como o próprio Freeman $(1999)$ e Carroll $(1979,1999)$.

Post, et al (2002) asseveram que a teoria dos stakeholders é adequada para aumentar o valor da empresa. Em resumo, a riqueza de uma organização está baseada na qualidade de suas relações com seus stakeholders. Observa-se, assim, a necessidade da consideração, pela empresa, do papel e da importância de todos os atores que mantêm uma interação e são por ela influenciados.

Conforme especificado anteriormente, uma forma de analisar stakeholders no que concerne à sua percepção frente à atuação social de uma empresa é por meio do modelo criado por Carroll em 1979, o qual mostra uma análise a partir de três dimensões distintas.

\subsection{Modelo Conceitual Tridimensional de Performance Social}

O modelo tridimensional de performance social foi proposto por Archie B. Carroll em 1979 com vistas a integrar conceitos e promover uma análise multidimensional da RSE. O autor considera três dimensões distintas no trato da RSE: as categorias; as ações ou os programas sociais que a empresa pode focar ou priorizar; e o tipo de resposta que a empresa pode apresentar em face de sua postura de relevância social.

Esses três ângulos de análise forçam a consideração das principais questões que devem ser analisadas na performance social de uma empresa (CARROLL, 1979). Para Welzel, et al, (2008), o modelo de RSE idealizado por Carroll (1979) é tido como um modelo explicativo fundamental do tema. A Figura 2 mostra o cubo que explana as três dimensões em questão:

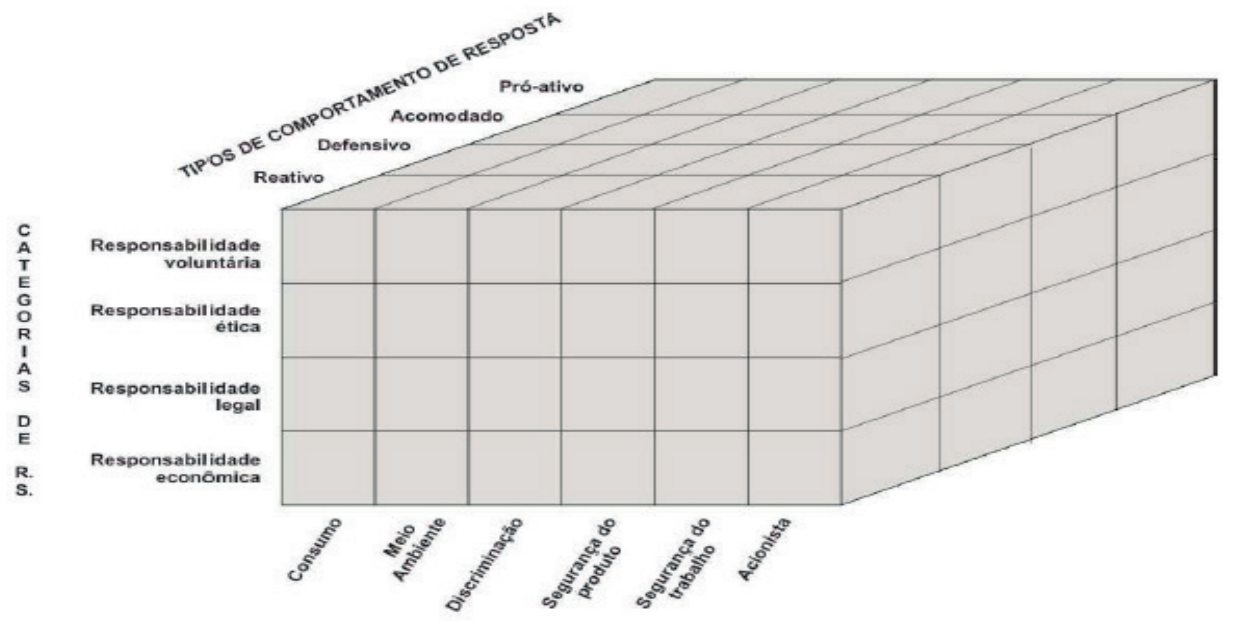

Figura 2: Modelo Conceitual Tridimensional de Performance Social Corporativa Fonte: Carroll, (1979) 
A primeira dimensão diz respeito às categorias de RSE, que estão relacionadas às responsabilidades ou obrigações do negócio. Situa-se aí a responsabilidade econômica, em que a empresa tem a necessidade de oferecer ao seu público produtos e serviços adequados e garantir o retorno financeiro a acionistas, sócios, fornecedores, funcionários e parceiros. Há, também, a responsabilidade legal, que determina que as leis e regulamentações formam a estrutura legal sobre a qual se espera que os negócios operem. A responsabilidade ética, por sua vez, considerada como a mais difícil de ser trabalhada e praticada nos negócios, implica a análise e reflexão ética na tomada de decisões na empresa. $\mathrm{E}$ a responsabilidade discricionária aborda os atos voluntários e que ficam por conta do julgamento individual dos gestores da organização.

É válido ressaltar que, para entender a complexidade da RSE nas organizações modernas, faz-se necessário incorporar uma visão mais vasta da sociedade, considerando o macro ambiente, suas necessidades e seus anseios, conforme explanam Carroll (1979) e Wood (1991). Nesse sentido, a estrutura do presente modelo aborda outra dimensão que consiste nas ações e nos programas sociais que podem ser foco de atuação social de uma organização.

Carroll (1979) aponta que tais ações e programas são diferentes para cada indústria, sendo sua consideração e relevância dependentes do contexto e dos stakeholders envolvidos com a firma. Essas ações podem estar ligadas à natureza de seus produtos ou relacionadas à cultura de uma organização e incluem ênfase na segurança do produto, segurança do processo ou do trabalho, meio ambiente, consumo e acionistas. $\mathrm{O}$ autor aborda que não necessariamente a empresa pode ter um desses focos no trabalho com questões sociais, ficando a cargo do pesquisador/gestor identificar quais áreas ou recursos uma empresa prioriza em suas ações socialmente responsáveis.

A forma de comportamento e resposta do gestor constitui a terceira dimensão do modelo de Carroll (1979). Para o autor, o termo geralmente usado para descrever esse aspecto é resposta ou responsividade social. Carroll (1979) segue a abordagem definida por lan Wilson (1975) apud Carroll (1979) em relação aos comportamentos e às respostas (responsividade social) de uma empresa. Os tipos de resposta podem ser:

a) Reativa - a empresa responde a uma questão social depois que ela tem seus objetivos ameaçados, ou seja, depois que algum problema interfere em seu efetivo funcionamento;

b) Defensiva - a empresa age para se proteger ou se defender de um desafio ou problema;

c) Acomodativa - a empresa alinha-se às exigências do governo ou da opinião pública;

d) Proativa - a empresa antecipa exigências que ainda não foram feitas.

Como pontua o autor, enfoques antes tidos em separado, como as formas de resposta social, as categorias e os focos de análise da empresa, foram colocados em conjunto, conforme três dimensões de uma mesma abordagem. O modelo foi sugerido para ser utilizado principalmente na área acadêmica, como uma base conceitual; no entanto, pode ser considerado um mecanismo para apreciação do entendimento dos stakeholders sobre determinadas questões ou atuação social de dada organização.

Evidencia-se que este modelo é um dos mais citados na literatura sobre RSE e é, também, característico de pesquisas sobre o tema. Estudos como os de Aligleri et al, (2003); Machado e Zylbersztjan (2004); Stadler (2007) e Zanca et al, (2008) foram fundamentados pela pesquisa de Carroll de 1979 ou fazem referência a ela. Alguns autores, ainda, verificam as lacunas desse modelo no que concerne a uma possível operacionalização, a exemplo de Pasa (2004). Constatase, também, que o modelo é considerado uma das principais referências conceituais de autores nacionais e internacionais. 
Além de estar presente em diversos trabalhos, esse modelo se assemelha conceitualmente e estruturalmente a muitos outros, semelhanças estas que são bastante significativas. As principais semelhanças encontram-se na convergência entre as dimensões econômica e legal de Carroll (1979) e econômica de Enderle e Tavis (1998) e a visão clássica defendida por Quazi e O'Brien (2000). A dimensão ética proposta por Carroll (1979) possui semelhanças com a dimensão ambiental de Enderle e Tavis (1998) e com a visão moderna apresentada por Quazi e O'Brien (2000). Finalmente, a dimensão discricionária do modelo de Carroll (1979) converge com a visão filantrópica preconizada por Quazi e O’Brien (2000). Wood (1991) teve como um dos focos de análise o modelo de Carroll (1979). Wartick e Cochran (1985) desenvolveram um modelo de análise social estruturalmente similar ao modelo tridimensional de performance social.

O modelo de Carroll (1979) serviu de base para a construção de muitos outros ao longo do desenvolvimento da RSE, conforme já especificado. Autores como Aupperle, Carroll e Hatfield (1985) realizaram um monitoramento da RSE a partir de pressupostos comentados pelo autor e chegaram a preconizar um modelo baseado na relação entre RSE e rentabilidade, evidenciando opiniões de executivos sobre tal entendimento. Esse modelo constituía uma pesquisa empírica e discutia questões econômicas e sociais nas organizações.

Wartick e Cochran (1985) desenvolveram um modelo conhecido como desempenho social corporativo. Este modelo é bem similar ao de Carroll (1979), uma vez que apresenta um grupo de princípios, processos e políticas para reunir responsabilidade, responsividade e alguns assuntos relacionados à gestão administrativa. Para os autores, é possível medir o desempenho das organizações por meio do resultado entre a interação e as relações das empresas (atuação social e linhas teóricas) com a sociedade (integralização da atuação das empresas). Tudo isso resulta no termo Corporate Social Performance (CSP), o qual Carroll já havia evidenciado em 1979.

No modelo de Cochran e Wood (1984), é possível verificar novamente a vinculação entre a lucratividade da empresa e suas ações de RSE, uma vez que, para os autores, a empresa deveria transformar suas ações sociais também em retorno econômico. Observa-se que, no modelo de Carroll (1979), já era possível observar essa preocupação com o retorno financeiro, principalmente na dimensão categorias (categoria econômica). No entanto, a diferença é que Cochran e Wood (1984) promoveram uma discussão acerca do papel e da contribuição da RSE para com o retorno econômico, algo que Carroll (1979) já havia feito em sua discussão sobre o papel da empresa como geradora de investimentos, pagadora de impostos e geradora de empregos.

Carroll (1979), ao revisar os conceitos discutidos no modelo supracitado, apresentou outro modelo denominado pirâmide de RSE. Nele há uma análise sobre as três principais opções de princípios éticos: gerenciamento imoral, amoral e moral (CARROLL 1979, 1999). Nesse modelo, ética e moralidade seriam sinônimos. A pirâmide de Carroll também é um modelo muito conhecido e discutido na literatura relacionada. Embora existam críticas, pelo fato de Carroll ter colocado as categorias na pirâmide em forma de hierarquia, sugerindo uma ordem preferencial entre as atuações sociais, a pirâmide de Carroll contribuiu para esclarecer e desenvolver ainda mais o tema RSE.

O modelo de Wood (1991) evidencia a RSE como responsividade social corporativa. Seu artigo chegou a apresentar ideias sobre um modelo que discutia os princípios, processos e resultados dos estudos acerca da RSE. O autor procurou viabilizar a mensuração dos resultados das práticas das ações sociais. Segundo Wood, negócio e sociedade combinam-se, constituindo uma única entidade. Esse autor foi o primeiro a tentar "operacionalizar" as práticas de RSE. Mas muitas de suas discussões podem ser vistas como similares ou o resultado do que Carroll evidenciava em 1979. Para uma aplicação ou observação dos conceitos e das práticas relacionadas à RSE, o cubo tridimensional fornece ainda maiores subsídios para que os empresários consigam 
tal objetivo com maior êxito.

No Brasil, é possível discutir o modelo de Ashley (2001) denominado modelo multidimensional, relacional e multidirecional para a responsabilidade social nos negócios (MRMRSN). $O$ referido modelo indica que a atuação empresarial no campo social deve basear-se no entendimento de que são as regras e os padrões sociais referentes às relações da empresa que definem os seus níveis de moralidade corporativa e respondem sobre até que ponto deve ir a atuação da RSE. Assim, as estratégias de gestão social devem basear-se em desafios éticos fundamentados em três tipos de relações/dimensões do modelo: relações político-sociais, relações core-business, relações de produção e de distribuição internas. O modelo MRMRSN possui efetiva relevância no campo da RSE, uma vez que apresenta a real importância da interação entre empresas e stakeholders e o papel que cada grupo possui na atuação social da organização.

Schwartz e Carroll (2003) discutiram em seu modelo dos três domínios as categorias econômica, legal e ética e suas características, em que é possível vislumbrar maiores detalhes sobre as referidas categorias comentadas preliminarmente em 1979.

Nesse sentido, observa-se a importância do modelo do referido autor para a construção do conceito e dos métodos de abordagem da RSE. A tridimensão do modelo de Carroll (1979) mostra ângulos de análise diferenciados, citados por muitos autores, que abordam aspectos internos e externos à empresa, os quais incluem os interesses, as singularidades e as necessidades sociais de seus stakeholders.

A partir disso, a seguir, apresenta-se o método que deu suporte à realização da presente pesquisa.

\section{MATERIAL E MÉTODO}

Segundo Triviños (2001), os estudos exploratórios permitem ao pesquisador o entendimento aprofundado de uma teoria para encontrar os elementos necessários que lhe permitam a elaboração de algum instrumento. Seguindo essa linha de raciocínio, efetivou-se inicialmente um estudo exploratório que possibilitasse apresentar evidências propedêuticas ao tema em questão. Buscou-se estudar e levantar questões e aspectos-chave de alguns dos principais estudos sobre RSE na literatura relacionada. A Tabela 1 apresenta uma síntese dos principais estudos que serviram para a construção das variáveis. Cada pesquisa propiciou uma contribuição à construção das variáveis de cada uma das três dimensões do modelo de Carroll (1979), já que cada pesquisa evidenciada e abordada integra uma área específica do modelo ou fornece informação relevante para cada parte dele. Assim, este estudo atendeu ao que foi proposto por Cooper e Schindler (2003), de que, por meio da exploração, os pesquisadores desenvolvem conceitos de forma mais clara, estabelecem prioridades, desenvolvem definições operacionais e melhoram o planejamento final da pesquisa.

A pesquisa exploratória forneceu suporte ao estudo das principais características de cada componente das três dimensões do modelo considerado, para que fosse facilitada a construção final das variáveis e seu objetivo ou definição. É importante mencionar que também serviram de suporte ao desenvolvimento final de cada variável alguns conhecimentos específicos dos pesquisadores, autores do presente estudo.

Para a construção dos instrumentos de pesquisa e roteiros de entrevista, utilizaram-se as variáveis criadas para cada uma das três dimensões do modelo. Para os questionários, foram colocadas as variáveis em uma escala likert, conforme será visto adiante. Para os roteiros de entrevistas, as variáveis foram colocadas em forma de questionamentos, de forma que os pesquisados estivessem à vontade também para realizar comentários além do que fosse perguntado. 
Ressalta-se que cada questão está relacionada a uma variável específica. Para que seja possível pesquisar muitas variáveis de uma mesma categoria, comportamento ou ação, pode-se tentar integrar as variáveis colocando suas palavras-chave em cada questão.

A seguir, observa-se como se deu a construção das referidas variáveis e, por conseguinte, a escolha dos instrumentos de pesquisa a partir de estudos e pesquisas coletados e examinados, conforme já especificado.

\section{RESULTADOS}

\subsection{Apresentação de Variáveis para Aplicabilidade do Modelo Tridimensional}

Foram criadas variáveis de análise para cada uma das dimensões do modelo, no sentido de fornecer suporte também para a criação de instrumentos de pesquisa específicos. Essa criação foi feita com base nos estudos apresentados na Tabela 1. O critério que contribuiu mais decisivamente para a escolha de tais estudos foi a apresentação de conceitos e exemplos de como podem ser entendidos os elementos de cada dimensão do modelo de Carroll (1979), conforme mostra a coluna "contribuição". Além disso, muitos deles comentam o referido modelo, apresentam a evolução da RSE, suas características e são os fundamentais quando se fala na literatura relacionada ao tema, conforme pode ser evidenciado na coluna "abordagem".

Tabela 1 - Síntese dos estudos que contribuíram à construção das variáveis

\begin{tabular}{|c|c|c|c|}
\hline Autor & Linha & Abordagem & Contribuição \\
\hline McGuire, 1963 & \multirow{2}{*}{$\begin{array}{l}\text { Pesquisadores } \\
\text { favoráveis à } \\
\text { Responsabili- } \\
\text { dade Social }\end{array}$} & $\begin{array}{c}\text { A empresa não possui só obrigações } \\
\text { legais e econômicas }\end{array}$ & $\begin{array}{l}\text { Fundamentou a construção da } \\
\text { responsabilidade econômica }\end{array}$ \\
\hline Davis, 1967 & & $\begin{array}{c}\text { A empresa tem obrigações legais e } \\
\text { deve promover benefícios econômi- } \\
\text { cos e sociais }\end{array}$ & $\begin{array}{l}\text { Apresenta como promover o } \\
\text { princípio discricionário conco- } \\
\text { mitantemente ao econômico }\end{array}$ \\
\hline Friedman, 1970 & $\begin{array}{l}\text { Visão economi- } \\
\text { cista }\end{array}$ & $\begin{array}{l}\text { O objetivo da empresa é apenas a } \\
\text { geração de lucros }\end{array}$ & $\begin{array}{c}\text { Apresenta de que forma se dá } \\
\text { a responsabilidade econômica } \\
\text { do negócio }\end{array}$ \\
\hline Sethi, 1975 & $\begin{array}{l}\text { Esquema de } \\
\text { Três Estados } \\
\text { para classificar }\end{array}$ & $\begin{array}{l}\text { Classificou as dimensões do compor- } \\
\text { tamento corporativo em nível macro }\end{array}$ & $\begin{array}{c}\text { Ajudou a identificar necessi- } \\
\text { dades e opiniões do ambiente } \\
\text { externo }\end{array}$ \\
\hline Freeman, 1984 & $\begin{array}{c}\text { Teoria dos } \\
\text { Stakeholders }\end{array}$ & $\begin{array}{l}\text { Mostra os grupos ou indivíduos que } \\
\text { têm interesse ou participam de algu- } \\
\text { ma maneira na organização }\end{array}$ & $\begin{array}{l}\text { Fundamentou a construção de } \\
\text { todas as variáveis, pois o obje- } \\
\text { tivo do modelo é diagnosticar } \\
\text { a percepção dos stakeholders }\end{array}$ \\
\hline $\begin{array}{l}\text { Carroll e Hoy, } \\
\quad 1984\end{array}$ & $\begin{array}{l}\text { Modelo estra- } \\
\text { tégico de RSE }\end{array}$ & $\begin{array}{c}\text { Mostra a integração entre políticas } \\
\text { sociais e gestão estratégica, discutin- } \\
\text { do elementos associados à compe- } \\
\text { tição }\end{array}$ & $\begin{array}{c}\text { Propiciou abordagem para a } \\
\text { dimensão Ações e Programas, } \\
\text { pois evidencia restrições e } \\
\text { oportunidades para a empresa }\end{array}$ \\
\hline $\begin{array}{l}\text { Wartick \& Co- } \\
\text { chran, } 1985\end{array}$ & $\begin{array}{l}\text { Modelo De- } \\
\text { sempenho } \\
\text { Social Corpo- } \\
\text { rativo }\end{array}$ & $\begin{array}{l}\text { Identificaram e mensuraram ações } \\
\text { e efeitos de Responsabilidade Social } \\
\text { por meio de princípios, processos e } \\
\text { políticas de trabalho }\end{array}$ & $\begin{array}{l}\text { Apresenta abordagem para a } \\
\text { dimensão comportamentos e } \\
\text { respostas / } \\
\text { Determinação de políticas efe- } \\
\text { tivas de RS para a área Ações e } \\
\text { Programas }\end{array}$ \\
\hline Wood, 1991 & $\begin{array}{l}\text { Modelo Perfor- } \\
\text { mance Social } \\
\text { Corporativa }\end{array}$ & $\begin{array}{l}\text { Discutiu os princípios de RS, os pro- } \\
\text { cessos de resposta e as atitudes de } \\
\text { comportamento }\end{array}$ & $\begin{array}{l}\text { Apresenta abordagem para a } \\
\text { dimensão comportamentos e } \\
\text { respostas/Princípio da Legali- } \\
\text { dade e gestão discricionária }\end{array}$ \\
\hline
\end{tabular}




\begin{tabular}{|c|c|c|c|}
\hline Swanson, 1995 & $\begin{array}{l}\text { Modelo De- } \\
\text { sempenho So- } \\
\text { cial Corporati- } \\
\text { vo Reorientado }\end{array}$ & $\begin{array}{c}\text { Apresentou os macro e micro princí- } \\
\text { pios de RSE, a cultura corporativa e } \\
\text { os impactos sociais }\end{array}$ & $\begin{array}{c}\text { Discute focos de atuação } \\
\text { social e seus impactos, que } \\
\text { basearam a dimensão ações e } \\
\text { programas }\end{array}$ \\
\hline SA 8000, 1997 & $\begin{array}{l}\text { Indicadores de } \\
\text { Responsabili- } \\
\text { dade Social }\end{array}$ & $\begin{array}{c}\text { Certificação para saúde e segurança } \\
\text { no trabalho, extinção do trabalho in- } \\
\text { fantil ou forçado, remuneração justa } \\
\text { e outros }\end{array}$ & $\begin{array}{l}\text { Apresenta explicações para a } \\
\text { responsabilidade legal e para o } \\
\text { comportamento proativo }\end{array}$ \\
\hline $\begin{array}{l}\text { Enderle e Tavis, } \\
\quad 1998\end{array}$ & $\begin{array}{l}\text { Modelo de três } \\
\text { dimensões de } \\
\text { Responsabili- } \\
\text { dade Social }\end{array}$ & $\begin{array}{l}\text { Discutiram sobre a dimensão econô- } \\
\text { mica, social e ambiental }\end{array}$ & $\begin{array}{l}\text { Explicita o papel mínimo e má- } \\
\text { ximo da ética para a dimensão } \\
\text { comportamentos de resposta }\end{array}$ \\
\hline $\begin{array}{c}\text { Quazi e } \\
\text { O’Brien, } 2000\end{array}$ & $\begin{array}{l}\text { Modelo de } \\
\text { duas dimen- } \\
\text { sões }\end{array}$ & $\begin{array}{l}\text { Demonstrou as dimensões ampla } \\
\text { e restrita da RSE, sendo respectiva- } \\
\text { mente relacionadas à filantropia e a } \\
\text { aspectos econômicos da empresa }\end{array}$ & $\begin{array}{l}\text { Demonstra, na filantropia, } \\
\text { fundamentos para os com- } \\
\text { portamentos acomodativo e } \\
\text { proativo }\end{array}$ \\
\hline $\begin{array}{l}\text { Schwartz e Car- } \\
\quad \text { roll, } 2003\end{array}$ & $\begin{array}{l}\text { Modelo de três } \\
\text { domínios }\end{array}$ & $\begin{array}{c}\text { Mostra as dimensões econômica, } \\
\text { legal e ética em forma de diagrama, } \\
\text { evidenciando uma sobreposição en- } \\
\text { tre elas }\end{array}$ & $\begin{array}{l}\text { Ensina que existe um entrela- } \\
\text { çamento entre as dimensões } \\
\text { de RSE, sendo a dimensão } \\
\text { filantrópica subjacente às de- } \\
\text { mais }\end{array}$ \\
\hline $\begin{array}{l}\text { Schwartz e Car- } \\
\text { roll, } \\
2007\end{array}$ & $\begin{array}{l}\text { Modelo Value, } \\
\text { Balance e Ac- } \\
\text { countability } \\
\text { (VBA) }\end{array}$ & $\begin{array}{c}\text { Discute sobre Responsabilidade } \\
\text { social das empresas, Ética nos Ne- } \\
\text { gócios, Gestão dos stakeholders, } \\
\text { Sustentabilidade e Cidadania Corpo- } \\
\text { rativa }\end{array}$ & $\begin{array}{c}\text { Proporciona } \\
\text { esclarecimentos à responsa- } \\
\text { bilidade ética e discricionária. } \\
\text { Mostra o papel dos stakehol- } \\
\text { ders, fundamentando todas as } \\
\text { variáveis }\end{array}$ \\
\hline
\end{tabular}

Fonte: Elaboração Própria

É importante destacar que, a partir do estudo dos modelos, a abordagem de cada um deles é resultante dos acontecimentos históricos e econômicos referentes a cada momento em que foram criados. Nesse sentido, foi possível vislumbrar como cada autor identificou as necessidades sociais a partir de distintos contextos. Mas a grande contribuição à elaboração das variáveis foi o próprio estudo de Carroll de 1979, uma vez que o autor também apresentou discussões sobre cada dimensão do modelo, o que serviu como base para criar cada afirmativa para as dimensões. Efetivou-se a pesquisa exploratória com base nos pontos de vista dos autores supracitados também como forma de complementar as argumentações e opiniões de Carroll.

Desse modo é possível evidenciar, para cada pesquisa mostrada na Tabela 1, as questõeschave ou os fundamentos que serviram de base para a construção de cada variável do modelo. Na coluna referente à abordagem, é possível verificar o que cada estudo abordou e trouxe de contribuição para a RSE e, por conseguinte, na coluna referente à contribuição, observa-se qual colaboração cada pesquisa em questão proporcionou à efetivação da aplicabilidade do modelo de Carroll (1979).

A partir destes estudos, criaram-se as variáveis expostas nas Tabelas 2, 3 e 4. É válido ressaltar que cada grupo de stakeholder (fornecedores, funcionários, clientes, consumidores etc.) possui compreensões, necessidades e relações distintas com determinada empresa e que, a partir desta constatação, foi necessária a criação de variáveis e instrumentos de pesquisa específicos. Assim, algumas variáveis podem ser abordadas na pesquisa com stakeholders internos e outras com stakeholders externos a uma empresa. Cada tipo de stakeholder está apto a responder por determinado assunto relacionado à organização (um consumidor não possui as mesmas informações sobre ações sociais que um gerente ou cliente e assim sucessivamente). Foram criadas variáveis para uma pesquisa com funcionários de setores diferentes, diretores, acionistas e agentes externos à organização (estes últimos podendo ser fornecedores, clientes, consumidores, comunidade, governo e parceiros). 
Evidencia-se, também, que os instrumentos de pesquisa construídos possuem o mesmo número de variáveis para cada categoria, resposta e programa do modelo tridimensional para que seja possível, assim, calcular, mediante recursos distintos, a média ou outros valores quantitativos encontrados por uma escala estabelecida, como exemplo a escala likert.

A primeira dimensão do modelo tridimensional consiste nas categorias de responsabilidade social, as quais Carroll (1979) identificou como econômica, legal, ética e discricionária. A Tabela 2 apresenta as variáveis construídas e sua descrição.

Tabela 2 - Variáveis Criadas para a Dimensão Categorias do Modelo Tridimensional

Categorias

Equilíbrio entre receitas e despesas

Satisfação dos clientes como indicador de desempenho do negócio

Investimento em estrutura física, treinamento dos funcionários e novos produtos

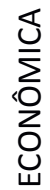

Monitoramento da produtividade dos funcionários

Realização de transações satisfató-
rias para stakeholders (internos externos)

Cobrança de preços convenientes ao poder de compra da demanda

Produção de bens e provisão de serviços de acordo com os requisitos da demanda

Efetividade no pagamento de impostos e tributos municipal, estadual e federal

O cumprimento integral das leis do trabalho e de obrigações contratuais

Adequação dos produtos ao Código de Defesa do Consumidor

Cumprimento da legislação ambiental

\section{Descrição}

Procura avaliar como os stakeholders conhecem a situação financeira da empresa

Evidencia se a preocupação em satisfazer os clientes faz parte da estratégia do negócio

Investiga o ponto de vista sobre as condições de trabalho em relação às instalações da empresa, a ocorrência de treinamentos e a prioridade para criação de novos produtos

Verifica se ocorre acompanhamento das atividades desenvolvidas, o que mostra a intenção de manter adequada produtividade e desenvolver produtos eficientes

Verifica como cada tipo de stakeholder pesquisado tem sua necessidade ou expectativa atendida pela empresa do ponto de vista das transações realizadas: pagamento de salários, cumprimento de contratos de compra e venda etc.

Constata a opinião dos stakeholders sobre se os preços dos produtos estão compatíveis com o poder de compra da demanda

Identifica a opinião sobre se os produtos ou serviços são feitos conforme o gosto ou a preferência da demanda - dependendo das características ou da natureza dos produtos ou serviços dispostos

dentifica o conhecimento dos stakeholders sobre o cumprimento da empresa em relação a suas obrigações tributárias

Procura verificar a percepção sobre o respeito às leis e sobre o cumprimento dos contratos com seus stakeholders

Constata o conhecimento dos stakeholders sobre se os produtos estão adequados às normas do código de defesa do consumidor

Verifica a opinião dos pesquisados sobre o alinhamento da empresa com normas ambientais requeridas para cada tipo de produção em particular 
Identifica, na opinião dos pesquisados, se as ações A existência e aplicação de um códi- sociais são fundamentadas em princípios éticos, bago de ética na empresa seados em um código de ética ou estrutura semeIhante

Respeito à integridade física e moral Avalia se a individualidade e particularidade dos de funcionários e clientes stakeholders são respeitadas pela empresa

Abertura ou procedimento confi- O procedimento confidencial mostra que existe a dencial na empresa para funcioná- preocupação de proporcionar bem-estar aos funciorios tratarem de questões proble- nários da empresa para que possam manifestar suas máticas satisfações e insatisfações no trabalho

Fomento de uma cultura interna Verifica o entendimento dos stakeholders sobre a culpara criação e adoção de valores tura da empresa e sobre o ambiente de trabalho do éticos ponto de vista ético

Existência de projetos e ações so- Identifica o conhecimento dos stakeholders sobre o ciais desenvolvidos pela empresa desenvolvimento de projetos sociais

Estímulo ao voluntariado nos clien- Analisa se a empresa incentiva seus stakeholders a tes internos participar das ações sociais de forma voluntária

Participação em organizações cívicas ou consideração aos problemas sociais da comunidade

Verifica se a empresa interage e promove benefícios à comunidade local

Disponibilidade aos funcionários de Diagnostica o comprometimento da empresa para aquisição de habilitações suplemen- dispor oportunidades para incremento das habilidatares des atuais dos funcionários

Fonte: Elaboração Própria

A segunda dimensão do modelo tridimensional enfoca os comportamentos de resposta ou, como é chamada por muitos autores, a responsividade social das empresas. Esses comportamentos foram identificados por Carroll (1979) como comportamentos de resposta reativa, defensiva, acomodativa ou proativa. As variáveis criadas e sua descrição podem ser observadas na Tabela 3.

Tabela 3 - Variáveis criadas para a dimensão Comportamentos de Respostas do modelo tridimensional

Respostas Variáveis Descrição

Fomento de ações sociais de- Verifica se as ações sociais são geradas porque existe um prinpois de protesto ou reivindicacípio de protesto ou reivindicações propriamente ditas por ções da sociedade parte da sociedade em relação a alguma prática da empresa

Ações sociais para viabilizar a Possibilita avaliar se, para os stakeholders, a empresa só toma mitigação de impactos negati- iniciativa para realizar algum tipo de ação social se sentir que vos provocados pela empresa seus objetivos estão ameaçados

Realização de auditorias fre- Verifica a percepção sobre até que ponto a empresa desenvolve quentes ações sociais somente para não sofrer sanções nas auditorias

$\$ \quad$ Revisão periódica das ações A revisão das ações sociais demonstra que a empresa procura sociais para conformidade com objetivos empresariais agir no sentido de se defender de um problema ou evitar que ele tome maiores proporções, estando em conformidade com os objetivos empresariais

Receptividade para relevância de problemas sociais ocasionados pela empresa

Avalia se a abertura da empresa é proporcionada pela intenção de se defender de alguma questão problemática causada por ela ou para manter uma relação confortável e reduzir a possibilidade de conflitos 


\begin{tabular}{|c|c|c|}
\hline Respostas & Variáveis & Descrição \\
\hline \multirow{4}{*}{ 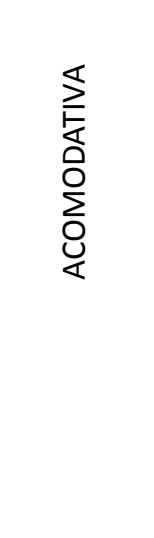 } & $\begin{array}{l}\text { Atuação social tendo em vista } \\
\text { o que a empresa necessita e o } \\
\text { governo ou sociedade solicita }\end{array}$ & $\begin{array}{l}\text { Forma de analisar se a justificativa de a empresa atuar socialmen- } \\
\text { te é o atendimento das expectativas do governo ou da sociedade }\end{array}$ \\
\hline & $\begin{array}{l}\text { Gestão administrativa em } \\
\text { acordo com as expectativas/ } \\
\text { necessidades dos funcionários }\end{array}$ & $\begin{array}{l}\text { Possibilita avaliar se a gestão da empresa tem a preocupação } \\
\text { de considerar as expectativas dos seus funcionários }\end{array}$ \\
\hline & $\begin{array}{l}\text { Os projetos sociais visam } \\
\text { cumprir as normas e a legisla- } \\
\text { ção governamental }\end{array}$ & $\begin{array}{l}\text { Forma de analisar se ações sociais da empresa são desenvol- } \\
\text { vidas somente para que ela se alinhe às exigências (normas) } \\
\text { ou opiniões do governo }\end{array}$ \\
\hline & $\begin{array}{l}\text { Institucionalização de proje- } \\
\text { tos educacionais, culturais ou } \\
\text { éticos, internamente ou na } \\
\text { comunidade local }\end{array}$ & $\begin{array}{l}\text { Verifica se a empresa mantém projetos abrangentes interna } \\
\text { ou externamente, os quais podem servir de base para agir } \\
\text { antes que problemas aconteçam. Permite verificar também o } \\
\text { nível de transparência e informação que a empresa disponi- } \\
\text { biliza sobre essas ações aos seus stakeholders }\end{array}$ \\
\hline \multirow[t]{3}{*}{ 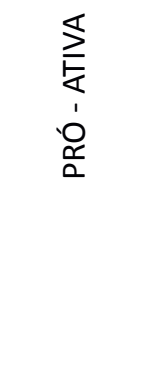 } & $\begin{array}{l}\text { Relação entre planejamento } \\
\text { empresarial e suas estraté- } \\
\text { gias sociais }\end{array}$ & $\begin{array}{l}\text { Constata até que ponto as ações sociais da empresa são } \\
\text { abrangentes, fazendo parte ou não de seu planejamento es- } \\
\text { tratégico. Essa relação caracteriza também uma maneira de } \\
\text { agir antecipadamente aos desafios e problemas e uma forma } \\
\text { de fomentar ações mais eficientes }\end{array}$ \\
\hline & $\begin{array}{l}\text { Ações sociais estão além das } \\
\text { expectativas dos stakeholders }\end{array}$ & $\begin{array}{l}\text { O estabelecimento de ações além das expectativas caracteri- } \\
\text { za um comportamento proativo }\end{array}$ \\
\hline & $\begin{array}{l}\text { Desempenho de projetos por } \\
\text { iniciativa própria }\end{array}$ & $\begin{array}{l}\text { Mostra a disponibilidade da empresa de desenvolver e criar } \\
\text { seus próprios projetos ou ações e de informar os stakeholders } \\
\text { sobre essas ações. }\end{array}$ \\
\hline
\end{tabular}

Fonte: Elaboração Própria

A terceira dimensão aborda as ações e os programas que podem ser o foco de atuação social de determinada empresa. Carroll (1979) identificou alguns desses focos como: a segurança do produto ou do trabalho, o consumo, o meio ambiente, a discriminação para com funcionários e os acionistas. A Tabela 4 apresenta as variáveis construídas e sua descrição: 
Tabela 4 - Variáveis Criadas para a Dimensão Ações e Programas do Modelo Tridimensional

\begin{tabular}{cl} 
Ações & \multicolumn{1}{c}{ Variáveis } \\
\hline & $\begin{array}{l}\text { Modificação e/ou retirada de pro- } \\
\text { dutos após sua distribuição quando } \\
\text { não adequados aos clientes ou con- } \\
\text { sumidores }\end{array}$ \\
$\sum_{\mathcal{S}}^{\circ}$ Disposição de informações técnicas \\
Realização de pesquisas de merca- \\
do
\end{tabular}

Verifica se a empresa tem flexibilidade para atender reclamações ou desconformidade dos produtos após sua comercialização

Relacionamento pós-venda satisfatório com o cliente

Pontua se a empresa disponibiliza as informações técnicas em seus produtos conforme as exigências requeridas

Verifica a prioridade da empresa em criar produtos que sejam apropriados para o consumo, estando de acordo com as especificidades dos consumidores

Disposição de informações sobre Pontua o interesse da empresa em disponibilizar informaeducação ou consciência ambiental ções ao público externo como forma de promover educação no âmbito externo ambiental

Enquadramento da empresa com Além de verificar a existência de certificação, permite idencertificação ambiental tificar o nível de conhecimento dos stakeholders sobre as características da produção da empresa

Tratamento e reutilização de água Pontua o conhecimento sobre a utilização de alguma tecnoproveniente da produção logia especializada para tratamento e reutilização de água

Disposição adequada de resíduos Verifica o conhecimento sobre a correta administração dos sólidos e gases poluentes resíduos da produção

Utilização de tecnologias limpas ou Identificar se a empresa busca novas tecnologias para evitar que reduziram a poluição danos ao meio ambiente

Desenvolvimento de projetos vol- Avalia se a empresa desenvolve projetos na comunidade tados à preservação do meio am- para preservação ambiental e se esse seria seu foco de atubiente ação social

Igualdade de condições salariais independente de sexo

Mostra a opinião dos stakeholders sobre a disposição dos salários, isto é, se a empresa faz distinção de salários entre homens e mulheres

Igualdade na ocupação de cargos de chefia a pessoas de qualquer raça

Pontua a opinião sobre se os cargos de chefias são ocupados ou sexo

Liberdade de escolha e prática re- Verifica a opinião dos pesquisados sobre a existência de pressão ligiosa por parte dos gestores em relação à escolha religiosa

Segurança para o emprego ou para Pontua sobre a ocorrência de discriminação na contratação a contratação de funcionários com e manutenção de funcionários que têm idade mais de 45 mais de 45 anos de idade anos

Ações para mitigação de discriminação social ou racial entre funcionários ou outros atores relacionados à empresa

Identifica as opiniões sobre o trabalho da empresa com atividades que envolvem a não discriminação no seu âmbito interno ou externo 


\begin{tabular}{|c|c|}
\hline Ações & Variáveis \\
\hline \multirow{5}{*}{ 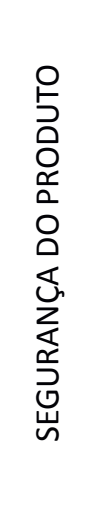 } & $\begin{array}{l}\text { Disponibilidade de informações so- } \\
\text { bre normas técnicas necessárias à } \\
\text { correta fabricação dos produtos }\end{array}$ \\
\hline & $\begin{array}{l}\text { Implantação de meios que bus- } \\
\text { quem a excelência do padrão de } \\
\text { qualidade }\end{array}$ \\
\hline & $\begin{array}{l}\text { Execução de medidas eficazes de } \\
\text { logística }\end{array}$ \\
\hline & $\begin{array}{l}\text { Ambiente sanitariamente adequa- } \\
\text { do para produção e estoque }\end{array}$ \\
\hline & $\begin{array}{l}\text { Produtos seguros à saúde de con- } \\
\text { sumidores }\end{array}$ \\
\hline
\end{tabular}

\section{Ações Variáveis}

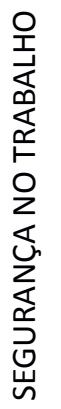

Fiscalização e monitoramento da utilização de equipamentos de proteção

Treinamentos para manejo adequado de ferramentas e máquinas

Fiscalização de infraestrutura para impedir danos à saúde dos funcionários

Diminuição do índice de acidentes nas operações do trabalho

Contínua prestação de contas aos acionistas da empresa

Mediação de interesses dos sócios acionistas com os objetivos de comprometimento social da empresa

Elaboração de programa de envolvimento de acionistas com projetos sociais desenvolvidos pela empresa

Estuda em conjunto com acionistas as

implicações da atuação social respon- Verifica se a atuação da empresa em projetos sociais sável na competitividade e no aumen- apresenta consequências positivas junto a acionistas to de lucratividade

Fonte: Elaboração Própria

Ressalta-se que essas variáveis servem de base para a construção de roteiros de entrevista estruturados ou semiestruturados ou de questionários distintos, os quais também foram construídos neste estudo. Estes instrumentos permitem, além da pesquisa da percepção dos stakeholders, com algumas adaptações, a realização de pesquisas com outros objetivos relacionados. A gestão da organização pode evidenciar como estão o andamento de suas iniciativas sociais, sua aceitabilidade ou rejeição, quais as atividades que devem ser priorizadas, quais os aspectos que estão sendo esquecidos ou, ainda, possibilita a realização de uma pesquisa de opinião como forma de inserir algum conjunto de stakeholder como atuante na organização.

\subsection{Parâmetros de Análise das Variáveis}

Para a construção dos instrumentos de pesquisa, procurou-se estruturar afirmativas correspondentes a cada uma das variáveis criadas no sentido de permitir ao pesquisado optar 
por seu nível de concordância e discordância em uma escala de opiniões que varia de 1 a 7 pontos. Assim, o nível mínimo (1) indica a total discordância com a existência da variável na empresa e o nível máximo (7) indica a total concordância com sua existência. Todos os valores a partir do número 1 indicam um aumento gradual do nível de concordância ou aceitabilidade da variável como existente na empresa a ser pesquisada. Essa existência ou não coloca a categoria, o comportamento de resposta ou o programa a que a variável se refere como característica da organização. Cada resposta contribui para a geração de uma média aritmética, sendo possível, assim, avaliar em cada dimensão a que obteve maior valor (média) segundo esse parâmetro. A Tabela 5 explana como se dá tal escala.

Tabela 5 - Parâmetros de Análise das Variáveis

\begin{tabular}{|c|c|c|c|c|c|c|}
\hline \multicolumn{7}{|c|}{ ESCALA DE VALORES NO QUESTIONÁRIO/OPINIÕES } \\
\hline 1 & 2 & 3 & 4 & 5 & 6 & 7 \\
\hline $\begin{array}{c}\text { Discorda To- } \\
\text { talmente }\end{array}$ & $\begin{array}{c}\text { Discorda } \\
\text { Muito }\end{array}$ & $\begin{array}{c}\text { Discorda } \\
\text { Pouco }\end{array}$ & $\begin{array}{c}\text { Nem con- } \\
\text { corda/nem } \\
\text { discorda }\end{array}$ & $\begin{array}{c}\text { Concorda } \\
\text { Pouco }\end{array}$ & $\begin{array}{c}\text { Concorda } \\
\text { Muito }\end{array}$ & $\begin{array}{c}\text { Concorda To- } \\
\text { talmente }\end{array}$ \\
\hline \multicolumn{7}{|c|}{ NÍVEL DE APLICABILIDADE/EXISTÊNCIA DA VARIÁVEL NA EMPRESA - PERCEPÇÃO } \\
\hline $\begin{array}{c}\text { Total diver- } \\
\text { gência da } \\
\text { Existência }\end{array}$ & $\begin{array}{c}\text { Muita diver- } \\
\text { gência da } \\
\text { Existência }\end{array}$ & $\begin{array}{c}\text { Pouca diver- } \\
\text { gência da } \\
\text { Existência }\end{array}$ & $\begin{array}{c}\text { Não carac- } \\
\text { terística da } \\
\text { dimensão }\end{array}$ & $\begin{array}{c}\text { Pouca Con- } \\
\text { cordância }\end{array}$ & $\begin{array}{c}\text { Muita Con- } \\
\text { cordância }\end{array}$ & $\begin{array}{c}\text { Total Concor- } \\
\text { dância }\end{array}$ \\
\hline
\end{tabular}

Fonte: Elaboração Própria

A partir da média gerada pela escala numérica, tem-se que, quanto maior a média, mais aplicável é a categoria, resposta ou ação/programa na empresa em estudo e vice-versa. Alguns softwares podem dar subsídios ao cálculo da média, de desvios padrão, da frequência de maior resposta e de outros parâmetros (resultados) a partir das respostas à escala de valores. Podem ser empregados, também, recursos estatísticos para análise de dados quantitativos podem ser empregados.

Os roteiros de entrevista semiestruturados são construídos com base nas afirmativas feitas a partir das variáveis, as quais foram recolocadas em forma de questões. É possível observar no estudo de Macêdo e Cândido (2011) como foram utilizados instrumentos para uma pesquisa qualitativa feita com stakeholders de uma empresa têxtil.

A partir do que foi abordado, é possível observar as considerações finais sobre esta pesquisa.

\section{CONSIDERAÇÕES FINAIS}

Muitos estudos de Carroll são citados nos fundamentos e estudos teóricos sobre RSE. Dentre esses, destaca-se seu estudo de 1979, que a presente pesquisa abordou para o fomento de seus parâmetros, e o seu estudo de 1991, momento em que o autor adotou uma única dimensão de seu estudo de 1979, as categorias de RSE, levando-as a uma visualização em forma de pirâmide. A pirâmide de Carroll é um dos estudos mais citados e considerados na literatura mundial sobre RSE, embora tenha recebido algumas críticas pelo fato de que transmite a ideia de hierarquia.

Nesse sentido, é válido o estudo do modelo de Carroll como ferramenta para o desenvolvimento social das empresas e de suas comunidades, principalmente dada a sua maior relevância nas últimas décadas. Ressalta-se, ainda, que a abordagem da RSE implica a consideração da gestão dos stakeholders e que, nesse sentido, o modelo de Carroll torna-se também relevante, já que reitera a importância desse tipo de gestão. Os stakeholders de uma organização são elementos-chave para a correta manutenção de uma rede de relacionamentos sustentáveis. 
Cada variável procura evidenciar as características principais de cada item das dimensões do modelo, sendo possível observar, na categoria legal, por exemplo, quais atividades caracterizam uma empresa com atividades sociais baseadas em requisitos legais ou, na categoria discricionária, quais atividades sociais são de natureza voluntária. Isso permite à empresa avaliar seus resultados, diagnosticar oportunidades e desafios e administrar seus pontos fracos, gerir suas atividades sociais de forma que seus stakeholders tenham uma compreensão fidedigna da realidade e tenham suas necessidades corretamente compreendidas.

Procurou-se estabelecer ou construir os parâmetros necessários para um estudo qualiquantitativo. Apesar disso, sugere-se a estudos futuros a realização de pesquisas somente quantitativas ou somente qualitativas, dependendo do objetivo almejado.

Reitera-se a necessidade de desenvolver estudos empíricos como forma de propiciar uma natureza prática à Responsabilidade Social nas empresas, bem como de continuar examinando e estudando as pesquisas relacionadas no Brasil e no mundo sobre o tema. Verifica-se que as empresas possuem o objetivo de melhorar e aperfeiçoar suas práticas sociais, algo que não é fácil inicialmente. O Brasil possui significativos problemas sociais, e, de acordo com Serpa e Forneau (2004), a RSE é mais valorizada e discutida no meio acadêmico e empresarial quando as ações sociais estão vinculadas à resolução de problemas básicos do país, tais como educação e saúde.

Recomenda-se o estudo deste modelo em empresas comprometidas com as comunidades e o entorno em que se inserem, dado o fato de haver poucas pesquisas com tal iniciativa. Pontua-se, ainda, a necessidade que há de trabalhar, concomitantemente à aplicação do modelo tridimensional e de suas variáveis criadas, a observação direta não participante ou participante. Esta permitirá confirmar os dados e as informações dispostas nos instrumentos de pesquisa, bem como inferir até que ponto cada dimensão é aplicada mediante a análise do ambiente em questão. Essa observação serve de suporte à validação das variáveis, uma vez que permite também a sua adaptação a realidades distintas.

Assim, torna-se relevante aprimorar um modelo que, ao mesmo tempo em que é importante para o tema RSE, torna possível o trabalho ou a consideração da correta gestão de stakeholders. A aplicação das variáveis construídas pode se dar em setores distintos se feitas as adaptações necessárias, levando em conta as singularidades de cada setor específico.

\section{REFERÊNCIAS}

Aligleri, L.; Aligleri, L.; Souza, M.; Schmitt, A.; Almeida, L. (2003), A Responsabilidade Social na Gerência de Produção: percepções, políticas e perspectivas na indústria de alimentos da região de Londrina. XXVII Encontro da Anpad - ENANPAD, Atibaia, SP, Brasil.

Ashley. P. A.; Macedo-Soares, D. (2001) Um Modelo Conceitual para a incorporação de Responsabilidade Social à Governança das relações negócio-sociedade. XXV Encontro da Anpad - ENANPAD, Campinas, SP, Brasil.
Aupperle, K. E., Carroll, A. B., Hatfield, J. D, (1985) An Empirical Examination of the Relationship between Corporate Social Responsibility and Profitability, Academy of Management Journal, 28(2), 446- 463.

Carroll, A. B. (1979), A three-dimensional conceptual model of corporate performance, Academy of Management Review, 4, 497-505. (1991), The Pyramid of corporate social responsibility: Toward the moral management of organizational stakeholders. Business Horizons, 34 (4), 39-48. 
Clarkson, M. B. E. (1995). A stakeholder framework for analyzing and evaluating corporate social performance. Academy of Management Review. 20 (1), 92-117.

Cochran, P. L., \& Wood, R. A. (1984) Corporate social responsibility and financial performance, Academy of Management Journal, 27(1), 4256.

Cooper, D.; Schindler, P. (2003), Métodos de pesquisa em administração. 7. ed. Porto Alegre: Bookman.

Dean, D. H. (2003), Consumer perception of corporate donations: effects of company reputation for social responsibility and type of donation. Journal of Advertising, 32 (4), 91104.

Donaldson, T.; Preston, L. E. (1995), The stakeholder theory of the corporation: concepts, evidence and implications. Academy of Management Review, 20 (1), 65-91.

Enderle, G.; Tavis, L. (1998), "A Balanced Concept of the Firm and Measurement of its longterm Planning and Performance". Journal of Business Ethics, 17 (11), 1129-1144.

Freeman, R. E. (1999), Divergent stakeholder theory. Academy of management review, New York, 24 (2) 233-236.

Friedman, M. (1970), The social responsibility of business is to increase its profits. The New York Times Magazine, (13), 16-18.

Grajew, O. (2001), Evolução e perspectivas da responsabilidade social. Jornal Valor Econômico. Ed. 301.

Heal, G. (2005), Corporate social responsibility: an economic and financial framework. The Geneva papers on risk and insurance - issues and practice, (30), 387-409.

McWilliams, A; Siegel, D. (2001), Corporate social responsibility: A theory of the firm perspective. Academy of Management
Review, 26 (1), 117-127.

Mohr, L. A.; Webb, D. J.; Harris, K. E. (2001), Do consumers expect companies to be socially responsible? The impact of coporate social responsibility on buying behavior. The journal of consumers affairs, 35 (1), 103-128.

Machado, C.; Zylbersztan, D. A (2004), Empresa Socialmente Responsável: o debate e as implicações. Revista de Administração Universidade de São Paulo, 39 (3), 242-254.

Macedo, N. M. M. N.; Candido, G. A (2011), Identificação das percepções de Responsabilidade Social Empresarial: um estudo qualitativo a partir da aplicação do modelo conceitual tridimensional de performance social. Revista de Gestão Social e Ambiental, 5 (1), 85-108.

Pasa, C. R. R. (2004), ECP-Social: um modelo de avaliação da performance social empresarial. Tese de Doutorado, Universidade Federal de Santa Catarina, Florianópolis, SC, Brasil.

Post, J. E.; Preston, L. E.; Sachs, S. (2002), Redefining the corporation: stakeholder management and organization wealth. Stanford: Stanford University Press.

Quazi, A.; O'brien, D. (2000), An empirical Test of a Cross-National Model of Corporate Social Responsibility. Journal of Business Ethics, Netherlands: Kluwer Academic Publishers, 25, 33-51.

Schwartz, M.; Carrol, A. B. (2003) Corporate Social Responsibility: a three-domain approach. Business Ethics Quarterly, 13,(4), 503-530.

Serpa, D. A. F.; Forneau, L. F. (2004) 0 Consumidor Ético Brasileiro: Realidade ou Fiç̧ão? Anais do XVII Congresso LatinoAmericano de Estratégia, Florianópolis, Santa Catarina, Brasil.

Stadler, A. (2007), Responsabilidade Social e Imagem Corporativa de uma instituição 
de ensino superior na percepção do corpo docente. Dissertação de Mestrado, Universidade do vale do Itajaí, Biguaçu, Brasil.

Triviños, A. N. (2001), Bases teóricometodológicas da Pesquisa Qualitativa nas Ciências Sociais - Idéias gerais para a elaboração de um projeto de pesquisa. Porto Alegre: Ritter dos Reis.

Wartick, S.; Cochran, P. (1985), The evolution of corporate social performance model. Academy of Management Review, 10 (4) 758-769.

Welzel, E.; Luna, M. M. M.; Bonin, M. A. S. (2008), Modelo da Dinâmica Interdisciplinar de Responsabilidade Social Corporativa: Contribuições Conceituais e Delimitação Teórica. XXXII Encontro da Anpad - ENANPAD, Rio de Janeiro, RJ, Brasil.

Wartick, S. L.; Cochran, P. L. (1985) The evolution of the corporate social performance model. Academy of Management Review, 10(4), 758-769.

Wilson, I. (2000), The new rules of corporate conduct. Westport, Connecticut: Quorum.

Wood, D. (1991), Corporate social performance revisited. Academy of Management Review, 16 (4) 691-718.

Zanca, J. F. R.; Quelhas, O. L. G.; Araújo, F. O.; Gosta, H. G. (2008), Comportamento organizacional e o contínuo ético da responsabilidade social corporativa: uma proposta de análise. II Simpósio Internacional de transparência nos negócios, Niterói, RJ, Brasil. 